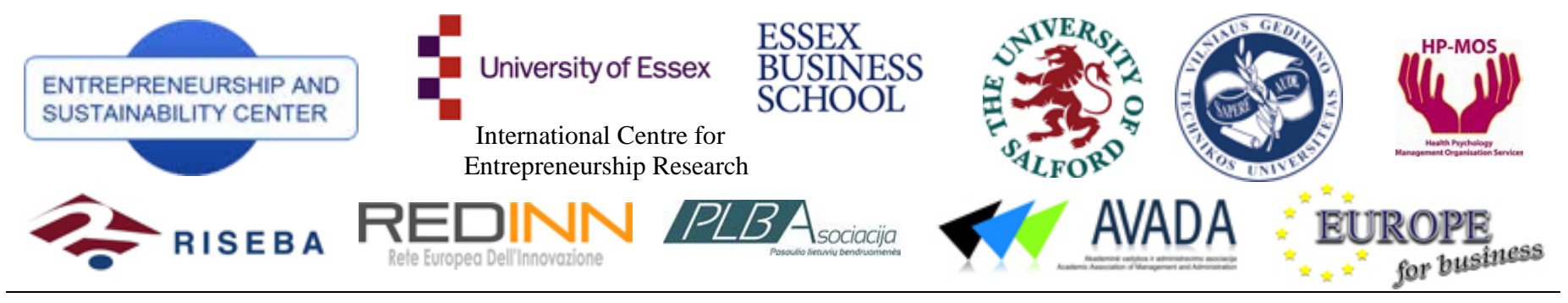

ENTREPRENEURSHIP AND SUSTAINABILITY ISSUES

ISSN 2345-0282 (online) http://jssidoi.org/jesi/

\title{
DATA-DRIVEN DEVELOPMENT IN THE SMART CITY: GENERATIVE DESIGN FOR REFUGEE CAMPS IN LUXEMBOURG
}

\author{
Daher, Elie' ${ }^{1}$; Kubicki, Sylvain ${ }^{1}$; Guerriero, Annie ${ }^{1}$ \\ ${ }^{1}$ Luxembourg Institute of Science and Technology, \\ 5, avenue des Hauts-Fourneaux. L-4362 Esch-sur-Alzette. G.D. de Luxembourg \\ E-mail: ${ }^{1}$ firstname.lastname@list.lu
}

Received 28 September 2016; accepted 15 November 2016

\begin{abstract}
The paper addresses computational design as a key technological asset in the development of the smart city. In particular, the research targets context-aware adaptation to usage requirements at urban fragment level. Indeed, cities' policy makers have to take into account many factors in a development policy, such as situational, technical or human-related factors as well as anticipating future usages. Moreover, nowadays, cities are key resources to answer growing humanitarian needs in terms of sheltering and camps. Indeed these situations are increasing due to different factors related to the nature, climate change or human activities. Resilience is therefore essential at the levels of districts, cities and territories. In Luxembourg, a public program aims to develop three container villages for refugees. The objective of this work is to help policy makers and humanitarians in the optimization of the spatial design of camps. The use of parametric modeling approach enables the optimization of space layout planning. It is applied on a case study allowing policy makers to explore scenarios for the decision-making in the camp space planning.
\end{abstract}

Keywords: Smart city, Computational design, Data-driven development, parametric modeling, Humanitarian need, Generative alghorithm, Space planning, Usage requirements.

Reference to this paper should be made as follows: Daher, E.; Kubicki, S. and Guerriero, A. 2017. Data-driven development in the smart city: Generative design for refugee camps in Luxembourg, Entrepreneurship and Sustainability Issues, $364-379$. http://dx.doi.org/10.9770/jesi.2017.4.3S(11)

JEL Classifications: C02, C61, C63, R52

Additional disciplines: Design, Environmental Engineering, Computer Science 


\section{Introduction}

Computational design is a technological paradigm involving Information Technology and Computing in the practice of design activities in multiple domains. The development of computing capabilities for design support started in the early 1980s, following major research achievements in the field of design theory (Gero 1990; Gero \& Kannengiesser 2004).

A wide research effort exists in "design computing" notably in the field of architecture and construction, where “construction informatics” forms an international scientific and industrial community (Türk, 2006; Björk, 1992). The application of computational design is also increasing in the Architecture, Engineering and Construction Industry (Boeykens, 2012). "Building Information Modeling” (BIM) and "Parametric Modeling” both reflect recent trends in computing design in academic research and market innovation. Another challenging aspect in design is the involvement of multi-expertise disciplines. Each expert addresses the design project according to his domain of expertise and his own viewpoint (Boton et al., 2013) which implies multiple views modeling in design support systems (Rosenman \& Gero 1996). Therefore the optimization in design requires procedures to merge these multiple viewpoints and criteria in order to support the decision-making.

At the level of city development, implications for computing support are also challenging. In the last decades, both city and land-related data modeling mainly addressed the representation of information layers in Geographical Information Systems. Reasoning and decision-support has mainly been developed in research literature through the application of Multi-Criteria Decision Analysis techniques (Malczewski 2006). An objectbased modeling approach is also applied in GIS systems (Shekhar et al. 1997). It notably enables the mapping and interrelation between building, infrastructure and land datasets in research (El-Mekawy et al. 2012; Peachavanish et al. 2006) as well as in commercial products such as Autodesk InfraWorks 360 or Vianova Novapoint.

On the other hand, the humanitarian response is a collection of interventions during and after crises to answer to the housing needs of displaced populations. The humanitarian design is quite similar to the usual collaborative approach in the design and construction industry. It involves multiple actors with different missions, interests and expertise (Balcik et al., 2010), such as the architectural design and construction (Kubicki et al., 2006). The planning, implementation and monitoring of humanitarian projects are the results of the collaboration of many stakeholders. The knowledge of these interventions is often based on previous experiences (Santos et al., 2013). The involvement of different stakeholders into the management process is very important as preparation and interaction of communities, business structures and NGOs with the public authorities can enhance awareness and response to various possible or present threats, help to mitigate consequences of crisis, and enable a recovery process for the population (Survila et al, 2016).

Moreover the diversity of stakeholders makes it sometimes difficult to find and implement the appropriate collaboration network (Charles et al., 2010). The humanitarian needs in terms of shelters and camps are increasing due to different factors related to nature or human activities. This article describes a research project aiming at studying the contribution of computing design methods for supporting humanitarianly in emergency situations. Worldwide, developing and managing refugee camps is increasingly significant, and the design must meet multiple constraints. Another aspect lies in time constraints. Indeed refugee camps planning should be completed as soon as possible to answer unpredictable flows of persons. 


\section{Design computing paradigms for the smart city}

\subsection{Challenges and operational concepts of the smart city approach}

The development of city and urban fragments perfomed by different kinds of planners involves "complex systems [dealing] with food supplies on an international scale, water supplies over long distances, and local waste disposal, urban traffic management systems, and so on; (...) and the quality of all such urban inputs defines the quality of life of urban dwellers (The Science Museum, 2004)", cited by (Caragliu et al. 2011). These authors operationally define a city as a "smart" system when "investments in human and social capital and traditional (transport) and modern (ICT) communication infrastructure fuel sustainable economic growth and a high quality of life, with a wise management of natural resources, through participatory governance”. One important challenge is to ensure a sustainable development for the population. Indeed, the sustainable development represents a commitment to advancing human well-being with the added constraint that this development needs to take place within the ecological limits of the natural resource (Korsakienè et al., 2011).

From infrastructure and policy development to the everyday urban life one can recognize that the trends are nowadays in inter-linking physical and digital spaces. Interrelations between these environments in the concept of the smart city usually describe the increased citizen-city interactions that can be enabled. Thus, beyond it, new forms of planning, design, and development as well as usage of urban spaces are to be defined in order to implement the smartness approach at city level.

Key societal challenges should be directly tackled by this new paradigm, and in particular the "global environmental challenges, with real and potential risks to our natural and built environment, including global climate change, increasing population and population density, increasing resource scarcity and both traditional and asymmetric forms of conflict” (Marsden and Rezgui, 2010). These authors proposed an evolution of sustainable urban planning approach in order to emphasize the dimension directly related to planning (land use, infrastructures, transport etc.) as well as the central role of ICT (Al Qahtany et al. 2013).

Computing researchers previously emphasized the importance of knowledge management principles and techniques. Semantic technologies have been applied to connect these multiple and heterogeneous data sources at the scale of the city. The City Service Ecosystem (CSE), for instance, is a digital environment for the governance of urban services, based on semantics for improved interoperability of city services (Celino \& Carenini 2014). Recently, (Anjomshoaa 2014) introduced the concept of Web of Buildings (WoB) as "a uniform information space that connects various BIM schemas and their corresponding instances (building) that are located in a specific geographic area [...]”.

\subsection{BIM and generative design for development of the city and urban fragment}

In the smart city environments, "urban processes, citizen engagements, and governance unfold through the spatial and temporal networks of sensors, algorithms, databases and mobile platforms" (Gabrys, 2014). This new way of considering the city implies new approaches for city planning which should contribute to its resilience. Design and engineering research communities provided important knowledge and experience to the smart city development issues. In particular the role of computing has been identified in spatial planning and building design for managing complexity, enabling the design of advanced morphologies, by enabling performance-driven design approach (Asl et al. 2014), as well as for managing information across projects' stakeholders (Turk, 2006).

The authoring of Building Information Models as well as the management of Information Exchanges are central concepts in the development and industrial implementation of Building Information Modeling. Indeed, BIM comprises both object-oriented modeling and process-related implications, as it is defined as a "new approach to 


\section{The International Journal \\ ENTREPRENEURSHIP AND SUSTAINABILITY ISSUES}

ISSN 2345-0282 (online) http://jssidoi.org/jesi/

2017 Volume 4 Number 3 (March)

design, construction and facility management in which a digital representation of the building process is used to facilitate the exchange and interoperability of information in digital format” (Eastman et al. 2011).

Beyond that, the application of computational design is increasing in the Architecture, Engineering and Construction Industry. "Parametric Modeling" reflects recent trends in computing design in academic research as well as in market innovation. It allows the designers to control the generation of visualized 3D objects from an overall logical computing script or scenario (Davis et al. 2011). They embed mathematical formulas, constraints and control functions to derive a geometric model from series of input data through a generative process, and thus enable a performance-driven reasoning. The characteristic of this approach is that it produces more than static geometry, i.e. a model with a collection of primitive shapes (Fernando et al. 2012). Parametric models embed dynamic and real time relationships within different components integrating mass amounts of information and constraints data, used in different applications.

At the urban level, computing brings a lot of opportunities to designers and developers, e.g. in simulating the impacts of land uses, estimating urban development strategies or enabling involvement of citizens in decisionmaking thanks to mobile applications or Virtual Reality tools. Openness, interoperability and integration of multiple datasets remain key challenges in the development and exploitation of such tools.

Regarding decision-making linked to development strategies at the scale of urban fragments, computational design approach enables design-support and simulation. The parametric relashionships defined in such approaches in addition to the constraints that will be "limiting" design options enhance the smart urban design. Some researches previously focused on the development of smart cities and the relation with the parametic modeling and computational design approaches. The intrusion of parametric methods into the urban context development was carried out within different projects and researches. (Steino et al. 2005) showed the capabilities of a parametric approach in urban design through a case study. According to this research, urban components share a similarity that can be defined parametrically. Aspects such as density, functions, forms, and spaces, can be translated into parameters. This approach helps in evaluating different scenarios and enables to reach an optimum solution. In addition, Saleh showed in his research that the usage of a parametric approach in urban design can lead to a sustainable result (Saleh and Al-Hagla 2012). In his research, he examines the use of a parametric method in sustainable urban development. The case study developed was the generation of an Arabian city taking into account constraints such as wind and solar envelopes. Different plug-ins for parametric systems have been developed also to study the urban behaviour and to propose some urban solutions for the usage requirement extension and emplacement.

\subsection{Computational applications for humanitarian needs}

Computational methods are more and more involved in the design process and the generation of forms for contemporary architecture, and it should be mentioned that a few applications appeared in the humanitarian field. Yeung focused on the application of digital architecture in low-tech reconstruction of the Solmon Islands (Yeung et al., 2011) targeting a set of parametric tools applied to latrine construction. Another example was the case study of the post-earthquake Haiti (Benros et al., 2011); automated systems were developed to create houses, this example focused on the resulting documentation as a set of construction drawings. Jinuntuya focused in his research on the use of digital tools and games' 3D virtual environment engines for developing a decision-making support system for humanitarian needs (Jinuntuya et al., 2007). Recently, the authors addressed the contribution of the parametric methods in emergency architectural design (Daher et al, 2014). The parameters needed for shelters have been identified and classified. The result was a parametric prototype taking into consideration physical parameters and allowing humanitarian stakeholders to generate sheltering solutions.

\subsection{Humanitarian situation in Europe and Luxembourg}

Factors related to natural environment and human activities are increasing the risk relating to housing. Migrants and refugees are still crossing into Europe, sparking a crisis as countries struggle to cope with the influx. 


\section{The International Journal \\ ENTREPRENEURSHIP AND SUSTAINABILITY ISSUES}

ISSN 2345-0282 (online) http://jssidoi.org/jesi/

2017 Volume 4 Number 3 (March)

Countries are trying to deal with this situation and to respond to the emergent demand for a rapid, sustainable and effective post-disaster response.

Luxembourg is directly involved in the refugee crisis in Europe and worldwide. Emergency refugee accommodation in Luxembourg is being provided at former hospitals and the Luxexpo (Exhibition and congress center). The CHL Maternity hospital on the Route d'Arlon provides 130 beds, the former speech therapy centre in Strassen has 300 beds, the Centre Hospitalier Neuro-Psychiatrique (CHNP) at Ettelbrück has 220 beds and Hall 6 of Luxexpo hosts 360 campbeds. In addition to this intervention, and in order to meet the growing influx of refugees in Luxembourg, the Luxembourg Government decided to create new temporary emergency centres by mid-2016: three "container villages" will be set up to take over as primary reception centres. The first three "container villages" to temporarily house asylum seekers in Luxembourg are to be installed in Steinfort, Mamer and Diekirch cities.

"The resilience is the ability of a system, community, or society exposed to hazards to resist, absorb, accommodate, and recover from the effects of a hazard (Jha et al., 2013)”. Focusing on human and social capital as well as ICT, Smart cities are more responsive to and efficient in facing a situation of risk. They become more resilient. The situation related to the influx of refugees requires of the city of Luxembourg adapting itself. Our proposition contributes to increase its resilience in this situation by supporting the phase of planning of refugee camps. The next sections present a design decision framework, accompanied with an experimental prototype, directly related to this context and inspired by real requirements observed.

\section{Data-driven decision framework}

\subsection{Requirements and technological choices}

The requirements for a design decision framework were centred on providing the ability to rapidly test scenarios of camp development on several terrains. The framework should enable to link usage requirements (mostly quantitative data) to an automatically generated possible spatial design, optimizing it by basing on constraints and limits identified by the user.

The software programmes Rhinoceros and Grasshopper were chosen for the development of this project. This is justified by the ability of the software to easily design and manipulate algorithms based on visual objects. Grasshopper a plugin of Rhino 3D has a set of predefined components classified according to their operation. These components perform geometric operations modeling. The connection of different components enables operations that do not exist by default in design software systems. According to its nature, each geometric operation is based on parameters that can be manually modified. The modification of parameters will result in real-time modification of the 3D geometry.

Beyond producing a geometrical representation of a design solution, another aspect of design computing is the multi-criteria or multidisciplinary design optimization (MDO), which has been developed in aerospace engineering mainly addressing technical design and focusing on quantitative aspects (Geyer et al., 2010). MDO provides a powerful means to support the design process. Genetic algorithm (GA) is one of the methods of optimization often used in architecture. It is a procedure based on Darwinian notions where selection and recombination of genes or operators are used among candidate solutions to achieve the best performance (Goldberg 1989). The strength of GA lies in its adaptability to fit any kind of problems. Initially a set of solutions is selected randomly to form the initial population, and then the optimization with GA focuses on making a set of individuals evolve, using crossover and mutation operations. GA has been used in many activities and fields. Poblete shows how GA can be used to generate possible solutions for buildings with low cost energy consumption (Poblete 2011). Multi-criteria evolutionary optimization was also used in urban design to automate the generation and evaluation of urban street patterns (Chee et al., 2013). The chosen system to 
implement the demonstrator is based on visual programming and containing plug-ins and Live Physics engine for interactive simulation and optimization directly within Grasshopper (e.g. Galapagos, Kangaroo).

\subsection{Using datasets in generative process}

\subsubsection{Variables}

Moving from an explicit design to a parametric model is a process where geometry is a result driven by the designer's inputs and data values, which can affect the form. This process is executing some "usual" design activities but more efficiently and in a more iterative way due to input variables. The modification of these variables gives more options to be evaluated in the design process. The parameters identified are based on numerical values related to physical forms, geometries and dimensions. These physical parameters can be easily expressed numerically, while contextual and climatic parameters are more complex to be translated into quantitative (or numerical) values. Such variables are implemented in our design definition as data inputs (through a link with an external dataset) and manipulated by the user thanks to ad-hoc sliders.

\subsubsection{Constraints}

Identifying limits for the design is important in order to eliminate undesirable results. Limiting the entries of variables will also lead the design to options satisfying all the usage needs and requirements. In other terms, these limits are called design constraints. Even numerical values, shapes or relationships bind objects and elements. Constraints can be grouped into two types:

a) The constraints related to quantitative numerical values and requirements such as the number of person by container and the maximum height of the building. These constraints will be implemented in the system definition as numerical values.

b) Other constraints are related to the contextual environment and contextual requirements. Graphical representation, shapes and relationships will determine design elements. In this project the contextual constraints are: the site, the program, and other requirements such as the mandatory superposition of toilet containers, services and others.

\section{Implementation}

\subsection{Summary}

This work makes the hypothesis that the requirements (in terms of design of the container village) and the constraints (related in particular to the programme and site conditions) can be connected to a parametric digital model. The generation of design options that fit the requirements involves the identification of an algorithmic definition implemented with the appropriate constraints and variables. The design process is therefore related to the site and to the input variables. Performing a preliminary constructability review is essential to start the implementation. The target terrain is examined in order to determine whether it has a specific topography to take into account and to define the site's physical constraints as well as its access.

After selection of the site, an optimization of the graphical space programme for usage areas is processed, while taking into account the site constraints and the requirements for relations across the different spaces. The final step is dedicated to the choice of the configuration layout for the containers.

\subsection{Optimization framework}

For the space planning, a force-based approach was used. Kangaroo - a plug-in for Grasshopper - adopts this approach for related geometric optimization applications. It embeds physical behaviour directly to the 3D modeling. Kangaroo contains various ways of generating the forces that can affect the particles (objects having masses, volume...) in the simulation. In our case study spaces are addressed as mass elements, i.e. particles in Kangaroo. 
Information regarding the orientation, the site limit and the relations between different spaces will be computed. These constraints are used to identify the position of each space.

The force-based approach drives the behaviour of spaces caused by the identified forces. Many types of forces can be combined in the Kangaroo plug-in for finding the final form. (https://docs.google.com/document/d/1XtW7r7tfC9duICi7XyI9wmPkGQUPIm_8sj7bqMvTXs/preview)

In our case study, we have combined the three following types of forces: (1) Plaw, (2) Springs from line, and (3) Pull to surface:

\subsubsection{Plaw}

This shows a power law force with exponent -1 , which means that the strength of the attraction is proportional to the inverse distance between the particles. This force was used to keep the particles (spaces) adjacent after the simulation process.

\subsubsection{Pull to surface}

This force is used to constrain or pull particles (spaces) to a defined surface. It was used to orient our spaces/particles position according to the following constraints:

- Orientation, where habitation clusters were "pulled" to the south in order to have more solar gain.

- Entrance, where the surfaces related to the entrance and service were "pulled" to the site access.

- Site limit, in order to maintain spaces inside the limit of the site, all of them were "pulled" inside the site limit. This operation was computed manually, by defining fictive surfaces representing the site limit. Alternative solutions were possible. However, the created definition helped us to execute the desired requirement.

\subsubsection{Springs from line}

This force was used to maintain the constraints related to the linking between spaces. Once the identification of the relations between different spaces defined, these relations were maintained after the simulation of the abovementioned forces by using the "springs" force.

On the other hand, the notion of space syntax was useful for understanding the relation between the multispaces, this component was used to express one aspect in the analysis and the optimization of spaces: identifying structural connections in the layout of the network. To achieve these connections between the spaces, it was necessary to introduce this calculation to a parametric environment. The Space Syntax plug-in aims to optimize this approach using a computational method in Grasshopper and Rhino 3D system.

\subsection{Application scenario}

Wars in the world have forced millions of people out of their homes and communities, some living in camps across different countries, and others having to restart their lives in foreign countries like Luxembourg. For the refugees coming to live in the Grand Duchy, there appears to be hope, as Luxembourg is providing 3 terrains where the construction and implementation of container villages will take place. Our demonstrator was based on a real case terrain situated in the municipality of Diekirch in northeastern Luxembourg. It consists of 3.6 hectares of land in front of the military barracks "Grand Duke Jean”. 
The Google Map's terrain is first transformed into a numerical entry in a 3D software system (Rhino 3D). A first analysis of the selected site is performed in order to identify the constraints that should be implemented in the algorithm definition for the macro-planning layout. The overall capacity expected for the village is 300 beds (600 in case of an emergency situation). A first design choice was to separate three distinct clusters, dedicated to three ethnographic groups based on the origins of refugees. The development of the village requires 7 spaces dedicated to (1) clusters, (2) reception area, (3) feeding centre, (4) educational area, (5) services, (6) gathering, and (7) entertainment.

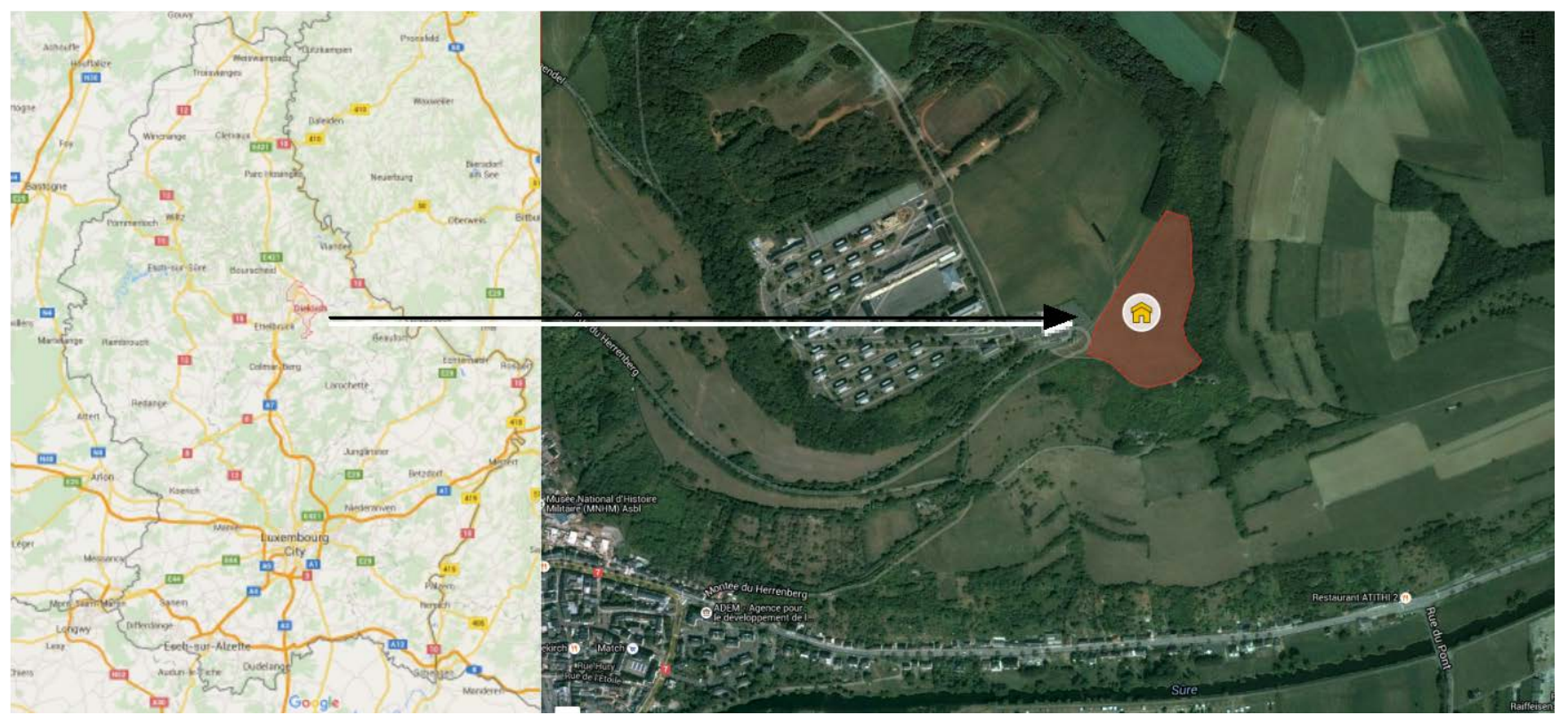

Fig. 1. Diekirch site in Luxembourg 
Table 1. Usage requirements regarding the living clusters, as input design dataset

\begin{tabular}{|l|r|}
\hline Clusters & 3 \\
\hline
\end{tabular}

\begin{tabular}{|c|c|c|c|c|}
\hline \multirow{8}{*}{ 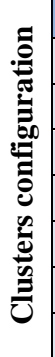 } & Origin ID & C1 & $\mathrm{C} 2$ & C3 \\
\hline & $\mathrm{Nb}$ of person & 75 & 100 & 125 \\
\hline & $\mathrm{Nb}$ of containers needed & 28 & 50 & 63 \\
\hline & Couples & 7 & 10 & 16 \\
\hline & Kids $(<18)$ & 16 & 24 & 34 \\
\hline & Singles & 15 & 20 & 41 \\
\hline & Old & 5 & 11 & 18 \\
\hline & Cluster surface & 2250 & 3000 & 3750 \\
\hline \multirow{7}{*}{ 总 } & $\mathrm{Nb}$ of latrines needed by cluster & 4 & 5 & 7 \\
\hline & $\begin{array}{l}\text { Optimum distance of latrine } \\
\text { from household (m) }\end{array}$ & \multicolumn{3}{|l|}{$<50$} \\
\hline & $\mathrm{Nb}$ of showers needed by cluster & 1 & 1 & 2 \\
\hline & Feeding center & \multicolumn{3}{|l|}{1} \\
\hline & Water waste tank retention & & & \\
\hline & Water point & 1 & 2 & 2 \\
\hline & $\begin{array}{l}\text { Distance from furthest dwelling to } \\
\text { water point (m) }\end{array}$ & \multicolumn{3}{|l|}{$<200$} \\
\hline
\end{tabular}

\subsection{Implementation of constraints}

In this application, the constraints are related to the site conditions and to the usage requirements in terms of respecting area and international standards.

\subsubsection{Contextual constraints}

Site accessibility: The accessibility of the site by roads will help in determining the land uses in dependence on this constraint (e.g. services and central reception area). In this village one access for the site from external roads is identified. This access was logically placed in the south part of the site (existing road).

Site orientation: The orientation for the land uses is defined according to the sunlight exposure. It is expected to maintain a comfortable environment for living. The southern part of the site is the one most exposed to the sun.

Site constructability: The identification of specific physical elements on site (river, trees...) helps in evaluating the site constructability in order to avoid these elements in the automatic design development. In the Diekirch site, no boundaries related to geographical aspects were identified. 


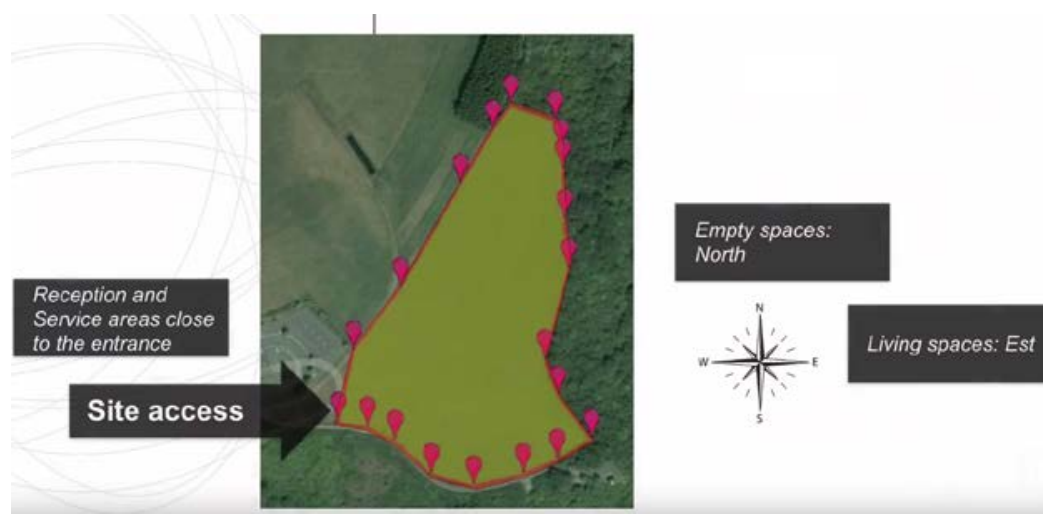

Fig. 2. Some of the site-related constraints identified

Usage requirements: The requirements in term of usages and the relationships between these usages are expected to be maintained in the design process. Space Syntax was used to generate the graphical representation of the relations between the different usages.

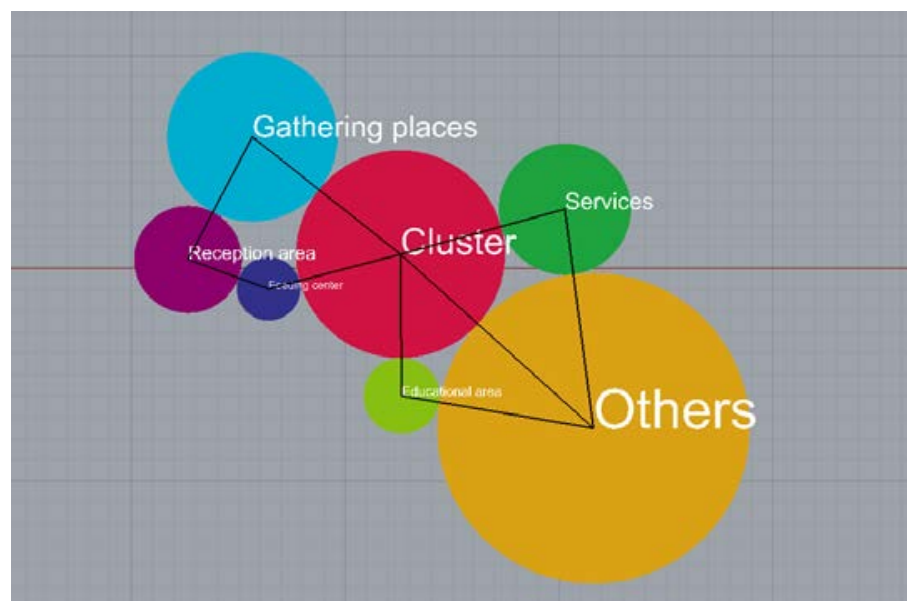

Fig. 3. Usage requirements relations, space syntax representation

This graphical representation is projected to the site conditions. Usage spaces are computed together with the identified constraints, in order to distribute and optimize the spaces of the site taken into account: (1) the constraints and (2) maintaining the relations between them. The relations between spaces were implemented using "Kangaroo" plug-in for "Grasshopper”. 


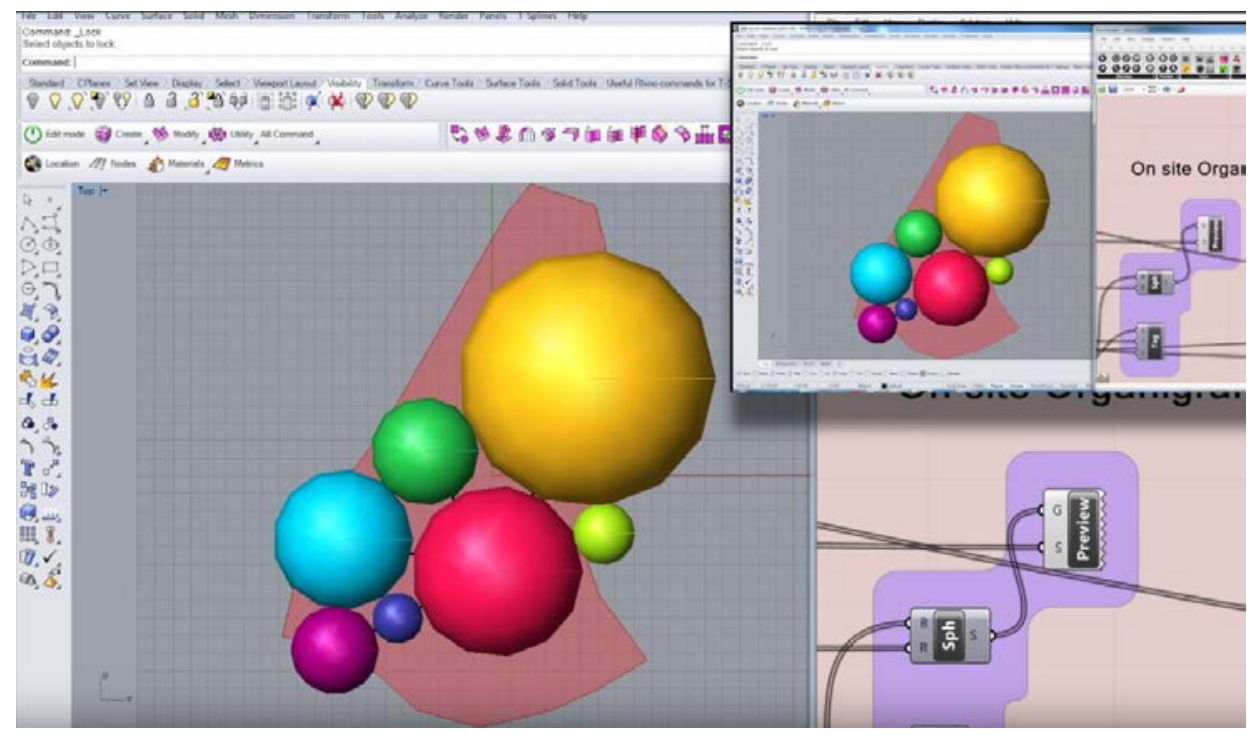

Fig. 4. On site optimization (Rhino 3D, Grasshopper)

\subsubsection{Numerical constraints}

Number of persons: The number of persons is defined as 2 persons per container; this will lead to have 150 containers in the village. As a result, the number of required sanitary facilities is a fixed value. These two values are implemented in the generative design process.

Dimension of the containers: This attribute can be interpreted sometime as constraint or as variable.

The dimension of the containers might change from one container to another, but in this example we have referred to a specific type of containers to use in the whole village.

Specific requirements: The design of containers should take into account that sanitary containers should be superposed in order to facilitate the evacuation of used water. In addition, the areas of different spaces have been respected according to international guidelines and standards.

\subsection{Implementation of Variables}

Problem solving requires the extraction of specific variables in terms of parameters (physical and contextual) and relations between them. Among the list of identified variables, parameters are chosen for the design and modeling demonstrator. The chosen parameters are specified according to their importance in the container village design. In this demonstrator, the chosen variables are mostly related to physical aspects. 


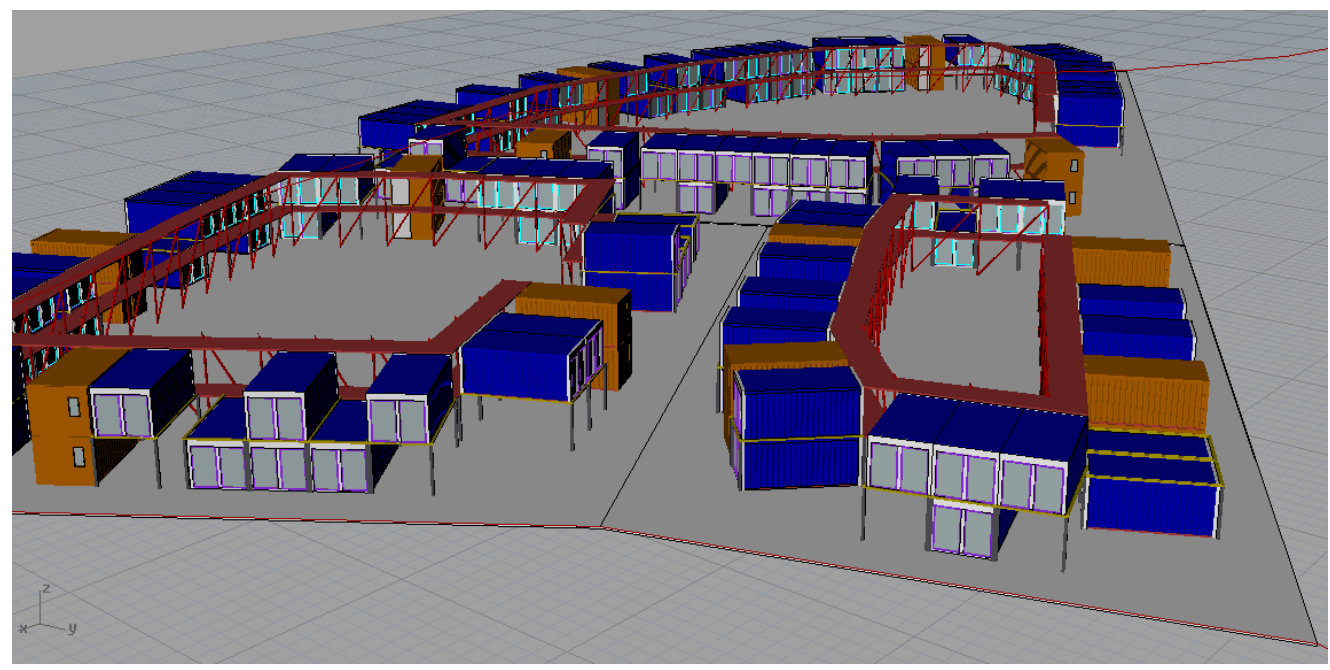

Fig. 5. Visualisation of the final automated configuration of clusters

These chosen variables are: (1) the general configuration layout of the clusters, (2) the definition of the entrance to the clusters, (3) the number of stories, (4) the parameters related to the passage between stories, (5) the structural elements. 


\section{ENTREPRENEURSHIP AND SUSTAINABILITY ISSUES}

ISSN 2345-0282 (online) http://jssidoi.org/jesi/ 2017 Volume 4 Number 3 (March)

\section{Conclusion}

This paper describes a research work carried out to investigate the potential application of computational design to assist humanitarian activities. It addresses the capability of parametric modeling in assisting the development of container villages for refugees, in order to help architects, humanitarian people and policy makers in the strategic planning and decision-making. It starts with developing a design process for the container village. This process is based on the optimization of the spatial layout related to expected usages, taking into account contextual constraints (e.g. site accessibility, orientation, etc.) and numerical constraints (e.g. containers dimensions or number of received migrants, etc.).

The output of this research consists of a prototype capable of generating a village of parametric containers from data requirements. This prototype is based on generative design where the constraints and part of the design process related to refugee camps are computerized. This approach contributes to the resilience of cities and territories facing the problem of migrant flows.

The current prototype has some limitations. The research focuses on the identification of parameters for modeling a prototype shelter and a layout of a camp. Aspects related to construction materials and costs are not considered in the implementation, at the moment.

The originality of the proposed idea relies on the innovative capacities of intervention in urban planning based on generative design for more responsiveness and efficiency. The parametric approach proposed should help in (1) enhancing the quality and reducing the time needed for the planning, especially in the initial steps, (2) enabling a smooth collaboration and information exchanges between different stakeholders, (3) allowing nonexperts to contribute to the development of urban planning, through the rapid 3D visualization, and (4) providing a generative decision-support computer system based on computable parameters.

As future research work, this generative and iterative process will be implemented in other use cases to generate design alternatives regarding the expected usages allowing deeper testing and evaluating of the effectiveness of this design process. In order to review this system, different experiments describing different scenarios will be created instantly by modifying the parameters to test the ability of the design process to answer scenarios similar to real cases. The research will also focus on the optimization of the interior elements of containers in order to answer the needs of refugees in terms of functions and usages. 


\section{References}

Anjomshoaa, A., 2014. Blending building information with smart city data. In S4SC'14: Proceedings of the Fifth International Conference on Semantics for Smarter Cities. 1280. CEUR-WS.org.

Al Qahtany, A.; Rezgui, Y; Li, H. 2013. A proposed model for sustainable urban planning development for environmentally friendly communities. Architectural Engineering and Design Management, 9(3): 176-194.

Asl, M. R.; Bergin, M.; Menter, A.; Yan, W. (2014). BIM-based parametric building energy performance multi-objective optimization. Education and Research in Computer Aided Architectural Design in Europe, 32: 1-10.

Balcik, B.; Beamon, B.; Kerjci, C.; Muramatsu, K.; Ramirez, M. 2010. Coordination in humanitarian relied chains: Practices, challenges and opportunities. Int. J. Production Economics. 126: 22-34.

Benros, D.; Granadeiro, V.; Duarte, J.; Knight, T. 2011. Automated design and delivery of relief housing: The case study of postearthquake Haiti. Proceedings of the 14th International Conference on Computer-Aided Architectural Design: 247-264.

Boeykens, S. 2012. Bridging building information modeling and parametric design. Proceedings of eWork and eBusiness in Architecture, Engineering and Construction (ECPPM 2012).

Boton, C.; Kubicki, S.; Halin, G. 2013. Designing adapted visualization for collaborative 4D applications. Automation in Construction, 36: $152-167$.

Caragliu, A.; Del Bo, C.; Nijkamp, P. 2011. Smart Cities in Europe. Journal of Urban Technology, 18(2): 65-82.

Celino, I.; Carenini, A. 2014. Towards a semantic city service ecosystem. In Proceedings of the Fifth International Conference on Semantics for Smarter Cities 1280: 3-8. CEUR-WS. org.

Charles, A.; Laura, M.; Tomasini, R. 2010. Collaboration networks involving humanitarian organizations - Particular problems for particular sector. 10th International Federation for Information Processing, Conference on Virtual Entreprises: 157-165.

Chee, Z.J.; Janssen, P. 2013. Exploration of urban street patterns. Multi-criteria evolutionary optimisation using axial line analysis. Proceedings of the 18th International Conference on Computer-Aided Architectural Design Research in Asia: 695-704.

Daher, E.; Kubicki, S.; Halin, G. 2015. A Parametric Process for Shelters and Refugees' Camps Design. Proceedings of the 33th eCAADe Conference: $541-548$.

Davis, D.; Burry, J.; Burry, M. 2011. Untangling Parametric Schemata: Enhancing Collaboration through Modular Programming. Proceedings of the 14th International Conference on Computer Aided Architectural Design Futures: 55-68.

Eastman, C.M.; Teicholz, P.; Sacks, R.; Liston, K. 2011. BIM handbook: A guide to building information modeling for owners, managers, designers, engineers and contractors. John Wiley \& Sons.

El-Mekawy, M.; Östman, A.; Hijazi, I. 2012. A Unified Building Model for 3D Urban GIS. ISPRS International Journal of GeoInformation, 1(3): 120-145.

Fernando, R.; Drogemuller, R.; Burden, A. 2012. Parametric and generative methods with building information modeling. Proceedings of the 17th International CAADRIA: 537-546.

Gabrys, J. 2014. Programming environments: environmentality and citizen sensing in the smart city. Environment and Planning D: Society and Space, 32: 30-48.

Geyer, F.; Beucke, K. 2010. An integrative approach for using multidisciplinary design optimization in AEC. Proceedings of the International Conference on Computing and Building Engineering icccbe 2010, Nottingham.

Gero, J.S. 1990. Design prototypes: a knowledge representation schema for design. AI Magazine, 11(4).

Gero, J.S.; Kannengiesser, U., 2004. The situated function-behaviour-structure framework. Design Studies, 25(4): 373-391.

Goldberg, David E. 1989. Genetic Algorithms in Science, Optimization, and Machine Learning, Reading, Mass.: Addison Wesley. 


\section{ENTREPRENEURSHIP AND SUSTA International Journal \\ ISSN 2345-0282 (online) http://jssidoi.org/jesi/ 2017 Volume 4 Number 3 (March)}

Jha, A. K.; Miner, T. W.; Stanton-Geddes, Z. 2013. Building urban resilience: Principles, tools, and practice. World Bank Publications.

Jinuntuya, P.; Theppipit, J. 2007. Temporary housing design and planning software for disaster relief decision support system. Proceedings of the 12th International CAADRIA: 639-644.

Korsakienė, R.; Breivytė, I.; Wamboye, E. 2011. Sustainable development and Human Development Index, Journal of Security and Sustainability Issues 1(2): 103-112.

Kubicki, S.; Bignon, J.C.; Halin, G.; Humbert, P. 2006. Assistance to building construction coordination towards multi-view cooperative platform. Proceedings of Journal of Information Technology in Construction (ITcon) 11: 565-586.

Marsden, T.; Rezgui, Y. 2010. Sustainable places at Cardiff University. Future Intermediate Sustainable Cities Conference, 23-25 November 2010, The British University in Egypt, Egypt.

Malczewski, J., 2006. GIS-based multicriteria decision analysis: a survey of the literature. International Journal of Geographical Information Science, 20(7): 703-726.

Peachavanish, R. et al., 2006. An ontological engineering approach for integrating CAD and GIS in support of infrastructure management. Advanced Engineering Informatics, 20(1):71-88.

Poblete, C. 2011. Evolutionary strategy to design optimized architecture. Proceedings of eCAADe29: 293-301.

Rosenman, M.A.; Gero, J.S. 1996. Modelling multiple views of design objects in a collaborative CAD environment. Computer-Aided Design. 28(3): 193-205.

Saleh, M.; Al-Hagla, K. 2012, Parametric urban comfort envelope, an approach toward a responsive sustainable urban morphology, International journal of social, Human and Technology, 6: 37-44.

Santos, A.L.R.; Capet, L.; Diehl, J.C. 2013 The value of collaborative design to address the challenges of the humanitarian sector. Proceedings of the 3rd International conference on integration of design, engineering and management for innovation: 301-310.

Shekhar, S.; Coyle, M.; Goyal, B.; Liu, D. R.; Sarkar, S. 1997. Data models in geographic information systems. Communications of the ACM, 40(4): 103-111.

Survila, A.; Rakšnys, A.; Tvaronavičienè, A.; Vainiutè, M. 2016. Systemic changes in disaster management in the context of public sector modernization, Journal of Security and Sustainability Issues 6(1): 37-52. http://dx.doi.org/10.9770/jssi.2016.6.1(3)

Steino, N.; Veirum, NE. 2005. A parametric approach to urban design, Tentative formulations of a methodology, Proceedings of the 3th International eCAADe, Lisbon: 679-686

Turk, Z. 2006. Construction Informatics: Definition and ontology. Advanced Engineering Informatics 20: 187-199.

Yeung, W.K.; Harkins, J. 2011. Digital architecture for humanitarian design in post-disaster reconstruction. International Journal of Architectural Computing. 9(1): 17-32. 


\section{ENTREPRENEURSHIP AND SUSTAINABILITY ISSUES \\ The International Journal}

ISSN 2345-0282 (online) http://jssidoi.org/jesi/ 2017 Volume 4 Number 3 (March)

\section{Authors}

Elie DAHER, Arch. He studied Architecture in Lebanon, (he is graduated from the Institute of Fine-Arts, department of Architecture, Lebanese University, Tripoli, Lebanon, in 2009). After four years of experience acquired in well recognized construction projects in several countries, he pursued the Master of "Global Design, specialty Architecture, Modelling and Environment" at the "Ecole Nationale Supérieure d'Architecture” of Nancy, France in 2014). Since February 2015, Elie Daher is a R\&D engineer at LIST. His applied works are covering the design computing, BIM processes, BIM management, BIM implementation, 3D coordination, 4D BIM simulation, parametric architectural modelling and optimisation.

ORCHID ID: 0000-0003-4423-2914

Sylvain KUBICKI, Dr. Arch. He studied Architecture in France and Switzerland. He was graduated from the Architecture School of Nancy, France, in 2003. He got a PhD in Architecture Science, with a thesis entitled "Assisting flexible coordination in building construction activity. A model-driven approach to design cooperation context visualization tools". He is now Senior Research and Technology Associate at Luxembourg Institute of Science and Tehnology, working on Building Information Modeling and construction technologies, both through research projects and consultancy services.

ORCHID ID: 0000-0003-2985-0378

Annie GUERRIERO, Dr. Arch. She is a senior research engineer at the Luxembourg Institute of Science and Technology (LIST, Luxembourg) where she workds since 2005. She is an architect graduated from the Victor Horta Institute (Brussels, 2001) and she performed a master in "Modelling and simulation of built spaces" (Henri Poincaré University, Nancy) in 2002. She obtained her PhD in April 2009 in Architecture Science at the INPL (Institut National Polytechnique de Lorraine). Her thesis, entitled "Representation of trust in the collective activity. Application to the coordination of the building construction activity", suggests a new approach for coordinating the AEC (Architecture, Engineering and Construction) activity based on trust assessment and multi-visualisation. This work received a distinction by the Academy of Architecture (France) in 2010. Currently, her research works is led at the LIST in the field of Building Information Modeling, smart systems and collective decision-making support dedicated to the construction sector.

ORCHID ID: 0000-0002-8804-1995

Copyright (C) 2016 by author(s) and VsI Entrepreneurship and Sustainability Center

This work is licensed under the Creative Commons Attribution International License (CC BY).

http://creativecommons.org/licenses/by/4.0/

(c) (i) Open Access 